\title{
Library Cooperation and Change
}

\begin{abstract}
Before cooperation will contribute in a major way to the solution of the problems of academic libraries, organizational and attitudinal changes must occur. These kinds of changes require much more local planning than is now taking place, and this planning must include attention to the requirements of organizational and behavioral change. If there is to be time for adequate planning, an individual with no other duties should be given the responsibility for cooperation. Participation in a formal organizational development program and the involvement of individuals from lower organizational levels and of library patrons in the design of cooperative programs will increase the likelihood that the activities necessary for successful cooperation will be performed.
\end{abstract}

\section{$\mathrm{S}$} SINCE THE EARLY 1970s academic library administrators, faced with static or decreasing budgets and the rapidly increasing costs of books and periodicals, have preached cooperation. Cooperation was seen as an answer to financial constraints on collection development and therefore on the availability of information to their clients. The logic of this response seems irrefutable. Libraries are service organizations with a long history of cooperation, ${ }^{1}$ precedents (interlibrary loan) and models (consortia) for resource sharing are present, ${ }^{2}$ and many of the books on the shelves of an academic library are used infrequently.

\section{COOPERATION HAS NOT \\ PROVIDED THE EXPECTED BENEFITS}

However, few cooperative programs that have significantly increased the availability or accessibility of information (especially current information) have been implemented at colleges or universities in the United States. Many new consortia have been established, existing interlibrary loan arrangements have been improved and special loan agreements negotiated, cooperative acquisition programs have been implemented, and innumerable meetings have been held. ${ }^{3}$ But the evidence in the literature indicates that only a minor impact can be attributed to these programs.

Robert F. Moran, Jr., is serials librarian, University of Illinois at Chicago Circle.
For instance, statistics for 1974-75 interlibrary loan activity in a sample of U.S. colleges and universities show that only an average of 1.79 percent of all recorded circulation in the colleges and 1.33 percent in the universities resulted from interlibrary loan activity. ${ }^{4}$ Reviews of cooperative acquisition programs list very few major successful programs that involve conscious division of collection-building responsibilities among academic libraries. Weber and Lynden mention only national plans like Farmington and PLA80 and the Center for Research Libraries (CRL). ${ }^{5}$ The only major U.S. program listed by Blackburn is CRL, ${ }^{6}$ and Edelman and Tatum in a recent article on collection development in university libraries cover cooperative programs in one paragraph, mentioning only CRL- and the ARL-sponsored program making dissertations available through University $\mathrm{Mi}$ crofilms. ${ }^{7}$ Johnson notes that even formally joined libraries follow centrally coordinated acquisitions policies in a minimal way. ${ }^{8}$ The Ohio College Library Center has made a major contribution to shared cataloging, but it is not certain that it has or can increase accessibility. ${ }^{9}$

In the introduction to the first section of Reader in Library Cooperation (1972), the editor, Michael Reynolds, states that it can be demonstrated "that library cooperation has not solved the important problems of the library, but only responded to their symptoms." 10 It does not appear that the 
situation is any different in 1978. I do not mean to suggest that no real value has resulted from the cooperative programs that exist, but that the results are insignificant when related to expectations, the models that have existed for some time, and the orientation of librarians toward cooperation.

\section{NEEDED ATTITUDINAL AND \\ ORGANIZATIONAL CHANGES}

Many reasons can be identified as likely causes for the failure of cooperation to achieve the expected results. Among those mentioned in library literature are: the prior importance of local programs, an unwillingness or inability to support cooperative programs with sufficient funds, and procedural and policy incompatibility; ${ }^{11}$ lethargy and lack of interest on the part of the librarians and senior clerical or technical personnel who staff the public service desks; ${ }^{12}$ the absence of reciprocity; ${ }^{13}$ and the attitude that assigns cooperative activity a low priority. ${ }^{14}$

These reasons do not explain the failure of cooperative programs to provide the expected relief for academic libraries as much as they point to one of the real causes for this failure. Librarians are not really committed to cooperation as a key means to the achievement of library goals. Despite periodic testimonies to the necessity of cooperation as exemplified by the 1976 Pittsburgh Conference on Resource Sharing, the majority of academic librarians continue to believe and act as though almost all needs of their clients can or ought to be met from the book collections and through the services of the client's library. This is not true, however; all needs cannot be met solely from this collection or through traditional kinds of activities.

The dramatic increases in the costs of published sources of information and static or decreasing budgets for collection development have combined with the exponential increase in the number of new publications to change the environment so drastically that traditional methods of collection and service are no longer adequate.

Academic libraries, and perhaps all libraries, have entered a new era of austerity in which the financial resources available will not be enough to enable them to continue to build their collections and operate as they did during the last two affluent decades. There is evidence that the ex- ponential growth rates of library collections and budgets are declining and the time has come to shift emphasis away from holdings and size to access and service. More realistic concepts of collection building will have to be adopted, and new patterns of service will have to be devised. ${ }^{15}$

A library's collection can no longer serve as the sole ordinary source of information to meet a client's needs. A new kind of library service must be developed.

To summarize, cooperative efforts to this point have not significantly increased access to information because basic attitudinal and methodological changes are necessary and the changes that have been made are essentially cosmetic. Before cooperative efforts will, to a significant extent, help academic libraries meet their goals, there must be major changes in the attitudes of librarians and library users and in the methods of library operation. Reliance on a library's legally owned materials as the primary and ordinary source for meeting clients' needs must be replaced by reliance on material owned by others as well as that owned by the library in question. Traditional methods of collection building and service must be replaced with more effective activities.

\section{REQUIREMENTS FOR MAJOR CHANGE}

The basic changes suggested here will not simply happen because they are necessary. A substantial commitment of time and resources is necessary so that problems can be analyzed, new policies and procedures designed, and changes implemented and accepted. The needs filled, as well as those not filled, by current practice must be known so that the new policies and procedures will answer all needs, not just those obvious at the time.

A major planning effort must address the implementation of a concept that proposes a change from owned collections as the primary source for meeting the information needs of the client to sharing as an equally appropriate source. Most significantly, since the attitudes and habits of librarians and library users will have to be changed with regard to the appropriate location of required information sources, library use by "outsiders," lead time required to provide information, and many other collection and service preconceptions, special attention 
must be given to the requirements of organizational and behavioral change.

The need for planning and for attention to the requirements of change suggested here is a local need. Substantial national and regional planning efforts have been underway for some time. The programs developed from these large-scale efforts will depend for success on the performance of each library in a network. It is at this level that inadequate time and attention are being given to preparation for cooperation. A commitment of time and resources to planning for cooperation and change is needed within each library. It is here that attitudes and procedures must change.

\section{ANALYSIS AND PLANNING}

Adequate analysis of current operations and planning for cooperation have not resulted from the chief librarian's willingness to attend meetings, the assignment of overall responsibility for cooperative programs to an already overburdened associate director, or the assignment of specific programs to individuals in charge of traditional functions. The responsibility for cooperative planning must be assigned to someone who has no other major responsibilities.

The central position resource sharing is likely to have and the number, kind, and scope of the changes required are justification for the creation of a new position rather than the temporary assignment of a senior official to oversee the development and implementation of cooperative programs. Also, individuals with current responsibilities are rarely relieved, in fact, of these responsibilities when given a new assignment. The choice of means by which each library assures sufficient planning time is not as important as the fact that the time is available.

If a new position is created, it should be at a senior level so that the individual in the position is aware of all major policy decisions and has the authority necessary to see new programs carried into action. Among the specific tasks to be assigned to the position are: (1) the analysis of current policies and procedures in the light of user needs, with a view toward developing cooperative programs to replace ineffective traditional activities, (2) the creation of planning mechanisms that involve the individuals who perform the activities that will be changed, (3) the creation of a comprehensive cooperative program, (4) the development of communication and rapport with users and with other libraries so that changes in traditional but no longer appropriate beliefs and expectations can be facilitated, and (5) the analysis and solution of legal problems that exist in relation to the guaranteed use of material owned by others.

The money necessary to fund a new position with the responsibility for cooperation will be no easier to find than money for other new needs, but funding for this need is available in most current academic library budgets. A reallocation of a portion of the book budget is an entirely reasonable response to the need for money to support the planning and organizing necessary to assure successful cooperation. The emotional and political unacceptability of this statement does not remove its truth.

It is generally agreed that no library can buy all the material it needs, and most also concur in the belief that our book selection methods leave much to be desired. Yet each year most academic libraries commit tens to hundreds of thousands of dollars to an admittedly hopeless task. Fifteen to thirty thousand dollars of this money spent to fund a position or office created to plan for and implement cooperation would contribute much more to the achievement of the library's goals than the books that would have been purchased with this money. The almost universal pressure from administrators and teaching faculty to buy more books makes such a reallocation extremely difficult. However, the likely long-range benefits argue for the attempt.

\section{ORganizational DEVELOPMENT}

It is suggested here that major organizational change is required if academic libraries are to take full advantage of cooperative programs. In this need to adapt to a new environment libraries differ little from most organizations. Today's rapidly evolving world is forcing all institutions to change or lose their effectiveness. ${ }^{16}$ In response to this need for organizations that can change, organizational development has become the subject of formal study and research, a literature of organizational development has 
been created, and a group of professionals whose purpose is the assistance and guidance of organizational change now exists.

Organizational development (OD) generally refers to a structured effort to increase organizational effectiveness through the use of concepts and data from the behavioral sciences. An OD program will have one or both of the following general goals: (1) the creation of an atmosphere, structure, and set of roles that allow the organization to be responsive to the demands of its environment and that facilitate change; and (2) the improvement of individual and group problem-solving and conflict-resolving abilities. The entire organization rather than specific problems is the focus of the effort. ${ }^{17}$

While the need in academic libraries for changes related to cooperation is not the only reason for a library to become involved in an organizational development program, this need provides one of the most compelling reasons to do so. A successful OD program will help create a structure and set of roles that will make change easier. It should also help develop the individual capacities and skills necessary for the development and implementation of new policies and procedures.

The Association of Research Libraries' Office of University Library Management Studies has designed an organizational development program called the Management Review and Analysis Program (MRAP). MRAP provides a process and formal set of procedures for use in the systematic investigation of top management functions in a research library. ${ }^{18}$ Among the benefits of the program are "staff development of a posture for self appraisal" and "the creation of an atmosphere for change." 19

Within the past two years the library at the University of North Carolina at Charlotte has developed the Academic Library Development Program (ALDP). Created for use in smaller academic and college libraries, ALDP "furnishes a means of developing the requisite knowledge and skill for coping with change and developing more effective working and operating practices." 20 MRAP and ALDP give to the administrator interested in developing a responsive organization programs developed specifically for research and academic libraries.

\section{BEHAVIORAL CHANGE}

Some of the traditional behavioral patterns of librarians and users must change if cooperative programs are to return maximum benefit. However, both experience and formal study ${ }^{21}$ tell us that long-standing habits do not change quickly or easily, and resistance to change in organizations is a commonly accepted and documented phenomenon. ${ }^{22}$ Librarians and users will not begin thinking and acting in terms of alternate sources of materials or different search time frames just because the logic and need for cooperation are apparent or because an administrator commits an institution to cooperation. Behavioral change is a multiphase process influenced by innumerable variables; appropriate changes will only occur to the extent that each stage and variable is dealt with successfully. Cooperation requires that time and attention be given to the requirements of behavioral change.

\section{A Change Model}

Research on change can provide some practical understanding and assistance to efforts to develop new behavior. The analysis of the change process originally developed by Kurt Lewin identifies three separate but related stages an individual or group must pass through before permanent change is achieved. Lewin saw current behavior (no change) as a process in a state of dynamic equilibrium with forces for change equal and opposite to forces resisting change. The process of change includes: (1) "unfreezing," i.e., an increase in the forces for change or decrease in the forces resisting change; (2) "moving" to a new level of equilibrium; and (3) "refreezing" at the new level through a new set of equal and opposing forces. ${ }^{23}$

In less technical terms, before individuals can be expected to change a particular behavioral pattern permanently they must be adequately motivated to change, they must discover and adopt appropriate new behavior, and the new behavior must be made enough of a habit to withstand the forces to return to the former pattern. ${ }^{24}$

The significant words here are adequately motivated and permanently changed. Few planners or administrators are unaware of the need to motivate employees and clients to accept new programs and procedures, 
but few new programs or procedures are implemented without difficulty or are they accepted quickly. A more thorough understanding of the change process and more attention to the elements blocking change will increase the likelihood of new behavior. It is a lack of this understanding and attention that is contributing to the failure of cooperation to achieve more success.

From among the several suggested mechanisms for unfreezing, moving, and refreezing, ${ }^{25}$ a few seem more appropriate for use in the situations under consideration.

\section{Unfreezing}

Individual realization of ineffective behavior. Perhaps the most effective way to motivate individuals to change a particular behavior is to convince them that their current activity is ineffective or unacceptable. This can be accomplished by the feedback of objective data that demonstrate ineffectiveness, or through the testimony of significant others (those whose opinion is important to the one performing the activity). For example, studies that show extremely low retrieval rates for books identified in the card catalog or excessively low use rates for the books on the shelves will move librarians to wonder if there is a better way to develop and index their collections. Testimony from respected teaching faculty on their lack of success when using the collection will also provide a motive to seek a better way. One of the practical means of providing these data and this testimony is the discussion of studies like the Pittsburgh study of book use $\mathrm{e}^{26}$ or the Case Western Reserve study of user frustration ${ }^{27}$ by groups of library staff and users. If these discussions could take place in a supportive environment where criticism was minimal and new kinds of behavior rewarded, change would be more likely to occur. ${ }^{28}$

Rewards and punishments. Specific rewards for those who change and punishment for those who don't have always been and still can be motivators. It is worth noting, however, that in his force field analysis, Lewin considered the removal of forces resisting change preferable to the increase of forces for change. The latter will increase tension and lead to increased resistance or cause other disfunctional reactions (higher aggressiveness, higher emotionality, lower constructiveness). ${ }^{29}$ It would seem, then, that attempts to move individuals to internal acceptance of new behavior would be more profitable than to force external compliance through rewards or punishments.

Also, recent studies on motivation ${ }^{30}$ have highlighted the importance of the individual's perception of the relationship between an activity and personal satisfaction. The objective existence of a reward will not motivate an individual to perform an action if that person does not believe that the reward follows as a result of the action. Since employees often see workplace rewards and punishments as an expected part of the environment, or as the result of favoritism or bias, an extraordinary effort tying a reward to an activity is required if the reward is to function as a motivator.

Research on the efficacy of pay as a motivator provides an example of this importance of tying a potential motivator clearly to the desired behavior. Pay will motivate higher performance only if the worker believes that higher pay is actually the result of higher performance; the relationship must be very clear and real. Thus the promise of a bonus tied to a specific level of performance will be more likely to motivate than the promise of an annual merit increase based on a general, subjective evaluation procedure. ${ }^{31}$ Therefore, if specific rewards or punishments are used to motivate library workers or users to change some of their habits, these motivators must be so designed and implemented that they are clearly seen as resulting from willingness or unwillingness to adopt behavior that enhances cooperation.

\section{Moving}

Moving to a new level of equilibrium, Lewin's second stage, involves finding appropriate new behavior to replace behavior judged ineffective. ${ }^{32}$ In libraries this search for more effective behavior is usually limited to higher organizational levels. Those who actually select or circulate the books and those who answer the reference questions often have little to say about a better way to perform their jobs. These individuals need to be involved in selecting new goals and means to these goals. Participation in 
decision making and group decision making have been shown to increase internal acceptance of a new activity, and acceptance increases the likelihood that the activity will actually be performed. ${ }^{33}$

\section{Refreezing}

The acceptance and practice of more appropriate behavior offers no assurance that the new activity will be permanent. The new behavior must be integrated within the personality of the changed individual, and the social forces that reinforced the former behavior must be dealt with. Unless the new activity fits with the individual's beliefs, attitudes, and other behavior, and unless it is acceptable to significant others, its performance will soon cease.

The failure of some training programs demonstrates the need for mechanisms designed to insure the permanence of a new habit. It has been shown that behavior developed at training sessions away from the job site disappeared as soon as the individual returned to his or her usual work environment. Resistance to change in the workplace and especially in other employees works against the continued performance of the new behavior. ${ }^{34}$

The introduction of change through means that encourage acceptance and integration at the second stage and planning that addresses change within the work group will increase the likelihood that the new habits will be permanent. If individuals are comfortable with the new behavior, that is, believe it appropriate for them and for the situation, they will be more able to resist counterforces in the environment. If the work group is changed or at least prepared for the change, the environment will support rather than resist the change.

\section{Planning for behavioral change}

This brief analysis based on Lewin's change model provides an argument for the involvement of librarians from lower organi- zational levels and of library users in the design of cooperative programs and procedures. Discussion of current behavior will help develop an awareness of its ineffectiveness and motivate these individuals to look for more effective behavior. Participation in the development of more effective activities and group decision making will increase acceptance of the new behavior; thus performance of this behavior will be more likely.

This analysis serves a second purpose. By providing an illustration of some of the thinking on change, it emphasizes the main point of this section: behavioral change is a multiphase process affected by many variables; change will be successful to the extent that these phases and variables are dealt with; and, therefore, planning for behavioral change is required if cooperation is to achieve its expected success.

\section{CONCLUSION}

This article begins with the suggestion that cooperation among academic libraries has not contributed as much to organizational goal achievement as would have been expected given certain characteristics of libraries and librarians. It is stated further that major organizational and attitudinal changes are necessary at the local level before cooperation will achieve maximum benefit and that these changes will occur only after each library commits substantial time and resources to planning for it.

This planning must address organizational and behavioral change as well as policy and procedural change. The assignment of the responsibility for the development of cooperative programs to an upper-level library administrator who has no other major duties will help assure adequate time for planning. A formal organizational development program and the involvement of individuals from all levels of the library and of library users in the creation of cooperative programs will facilitate necessary change.

\section{REFERENCES}

1. Joe W. Kraus, "Prologue to Library Cooperation," Library Trends 24:169-82 (Oct. 1975).

2. David C. Weber and Frederick C. Lynden, "Survey of Interlibrary Cooperation," in Joseph Becker, ed., Interlibrary Communica- tions and Information Networks (Chicago: American Library Assn., 1971), p.69-84.

3. David C. Weber, "A Century of Cooperative Programs among Academic Libraries," College \& Research Libraries 37:205-21 (May 
1976).

4. Ibid., p.217.

5. Weber and Lynden, "Survey of Interlibrary Cooperation," p.74-76.

6. Robert H. Blackburn, "Interlibrary Cooperation," in Jerrold Orne, ed., Research Librarianship, Essays in Honor of Robert B. Downs (New York: Bowker, 1971), p.51-73.

7. Hendrik Edelman and G. Marvin Tatum, Jr., "The Development of Collections in American University Libraries," College \& Research Libraries 37:237 (May 1976).

8. Richard D. Johnson, "Joint Academic Libraries," Advances in Librarianship 5:346-47 (1975).

9. Karl Nyren, "Resource Sharing in Libraries," Library Journal 101:2336-39 (Nov. 15, 1976).

10. "Theoretical Considerations of Library Cooperation," in Michael Reynolds, ed., Reader in Library Cooperation (Washington: NCR Microcard Editions, 1972), p.3.

11. Richard M. Dougherty, "Paradoxes of Library Cooperation," Library Journal 97:1768-69 (May 15, 1972).

12. David C. Weber, "Resource Sharing Prospects," News Notes of California Libraries 70:5 (1975).

13. G. Flint Purdy, "Interrelations among Public, School and Academic Libraries," in Reynolds, Reader in Library Cooperation, p.114.

14. John P. McDonald, "Interlibrary Cooperation in the United States," in Warren M. Tsuneishi, and others, eds., Issues in Library Administration (New York: Columbia Univ. Pr., 1974), p.131.

15. Richard De Gennaro, "Austerity, Technology, and Resource Sharing," Library Journal 100:923 (May 15, 1975).

16. John W. Gardner, Self Renewal, the Individual and the Innovative Society (New York: Harper \& Row, 1963).

17. Newton Margulies and Anthony P. Raia, Organizational Development, Values, Process, and Technology (New York: McGraw-Hill, 1972), p.1-2; Fred C. Pearson, Howard A. Sulkin, and Wallace G. Lonergan, Managing Organizational Improvement: The Role of the Design Groups (Chicago: Industrial Relations Center, Univ, of Chicago, 1971), p.1-7; Kenneth N. Wexley and Gary A. Yukl, Organizational Behavior and Industrial Psychology (New York: Oxford, 1975), p.283-84.

18. Duane E. Webster, "The Management Review and Analysis Program: An Assisted Self-Study to Secure Constructive Change in the Management of Research Libraries," College \& Research Libraries 35:115 (March 1974).

19. Ibid., p.122-23.
20. P. Grady Morein, and others, "The Academic Library Development Program," College b Research Libraries 38:41 (Jan. 1977).

21. Paul Hersey and Kenneth H. Blanchard, Management of Organizational Behavior (Englewood Cliffs, N.J.: Prentice Hall, 1972), p. 9-22.

22. Paul Lawrence, "How to Deal with Resistance to Change," Harvard Business Review 47:4-12, 166-74 (Jan./Feb. 1969).

23. Kurt Lewin, "Frontiers in Group Dynamics: Concepts, Method and Reality in Social Sciences; Social Equilibria and Social Change," Human Relations 1:34-35 (June 1947).

24. Edgar Schein, "Personal Change through Interpersonal Relationships," in Warren G. Bennis, and others, eds., Interpersonal Dynamics (Homewood, Ill.: Dorsey, 1968), p. $339-40$.

25. Edgar Schein, "Management Development as a Process of Influence," Industrial Management Review 2:56-77 (May 1961); Edgar Schein, "Personal Change through Interpersonal Relationships," p.340-66; Dale E. Zand and Richard E. Sorensen, "Theory of Change and the Effective Use of Management Science," Administrative Science Quarterly 20:532-45 (Dec. 1975).

26. Thomas J. Galvin and Allen Kent, "Use of a University Library Collection," Library Journal 103:2317-20 (Nov. 15, 1977).

27. T. Saracevic, and others, "Causes and Dynamics of User Frustration in an Academic Library," College \& Research Libraries 38:7-18 (Jan. 1977).

28. Edgar Schein, "Personal Change through Interpersonal Relationships," p.340-43.

29. Kurt Lewin, "Group Decision and Social Change," in Theodore Newcomb and Eugene L. Hartley, eds., Readings in Social Psychology (New York: Holt, Rinehart and Winston, 1947), p.342.

30. J. G. Hunt and J. W. Hill, "The New Look in Motivational Theory for Organizational Research," Human Organization 28:104-109 (1969).

31. Edward E. Lawler, "Using Pay to Motivate Job Performance," in Wexley and Yukl, Organizational Behavior and Industrial Psychology, p.56-72.

32. Edgar Schein, "Personal Change through Interpersonal Relationships," p.348-55.

33. Kurt Lewin, "Frontiers in Group Dynamics: Concepts, Method and Reality in Social Sciences; Social Equilibria and Social Change," p. $35-36$.

34. Edgar Schein, Organizational Psychology (Englewood Cliffs, N.J.: Prentice-Hall, 1965), p. $37-38$. 